\title{
THE
}

\section{Consumer Subjectivity in the Age of Internet: The Radical Concept of Marketing Control Through Customer Relationship Management}

\author{
Detlev Zwick \\ York University, dzwick@schulich.yorku.ca \\ Nikhilesh Dholakia \\ University of Rhode Island, nik@uri.edu
}

Follow this and additional works at: https://digitalcommons.uri.edu/cba_facpubs

Part of the Marketing Commons, Other Business Commons, and the Other Philosophy Commons Terms of Use

All rights reserved under copyright.

\section{Citation/Publisher Attribution}

Zwick, Detlev, and Nikhilesh Dholakia. Consumer Subjectivity in the Age of Internet: The Radical Concept of Marketing Control Through Customer Relationship Management. Information and Organization vol. 14, no. 3 (July 2004): 211-236.

DOI: 10.1016/j.infoandorg.2004.01.002

This Article is brought to you for free and open access by the College of Business at DigitalCommons@URI. It has been accepted for inclusion in College of Business Faculty Publications by an authorized administrator of DigitalCommons@URI. For more information, please contact digitalcommons-group@uri.edu. 


\section{Consumer subjectivity in the Age of Internet: The radical concept of marketing control through Customer Relationship Management}

Detlev Zwick, Marketing Department, York University, Canada.

Nikhilesh Dholakia, Marketing, E-Commerce, and Management Information Systems Areas, University of Rhode Island, USA.

The authors would like to acknowledge research support from the Research Institute for Telecommunications and Information Marketing (RITIM) at University of Rhode Island.

The authors would like to thank John De ighton, Eric Arnould, Jonathan Schroeder, Eileen Fischer, Alladi Venkatesh, for their helpful comments on earlier drafts of this paper. We also thank the anonymous reviewers whose help in improving this manuscript is greatly appreciated. 


\title{
Consumer subjectivity in the Age of Internet
}

\begin{abstract}
In this paper we present a poststructuralist analysis of customer database technology. This approach allows us to regard customer databases as configurations of language that produce new and significant discursive effects. In particular, we focus on the role of the databases and related technologies such as customer relationship management (CRM) in the discursive construction of both customers and customer relationships. First, we argue that organizations become the authors of customer identities, using the language of the database to configure customer representation. From this perspective, we can see the radical innovation that the customer database brings to the organizational construction of its market: the emergence of the individualized customer. The cultural novelty of the database - ignored by instrumental analyses of information technology - also requires a theoretical reconceptualization of the notion of virtual identity. Against existing positions we posit a non-essentialist theory of virtual identity where the subject is constituted outside the immediacy of consciousness and thus emerges as the result of the technological and linguistic context in which it was produced. Second, we take our analysis of the discursive construction of the customer further by proposing that the emergence of the individualized customer was the prerequisite of the social construction of customer relationship management as one-on-one affair between the customer and the organization. We suggest that this is a limited and limiting understanding of the concept of relationship especially if the one-on-one relationship is placed in a computer-mediated environment (CME). By mobilizing theories of play developed in the fields of humancomputer interaction and consumer research, we propose that organizations would benefit from opening up the current discourse on customer relationship management to include relationships between customers, customers and non-customers, and customers and the virtual organization.
\end{abstract}

Keywords: Poststructuralism; Subjectivity; Database marketing; Consumer Agency; Virtual identity; Foucault; Customer relationship management; Play. 


\section{Introduction}

Information technology is more than a tool; it is a mode of representation (Bolter, 2001a; Landow, 1992; Sotto, 1997). Yet, as Sotto (1997) points out, most analyses of technology - and in particular of information technology - look for and evaluate solely the instrumental value of their object of study. For instrumentalists, characteristics of technology worth looking at are limited to those that influence efficiency. Thus, according to the normative view of the instrumental paradigm - what the philosopher of technology Andrew Feenberg $(1991,1999)$ calls the functional theory of technology one technology is deemed superior to another if it improves the efficiency with which its users can perform a specific task. Thus, to paraphrase Heidegger (1977), instrumentalist and functionalist categories of analysis remain blind to the cultural and social questions concerning technology such as what kind of subject (e.g., worker, manager, consumer) emerges within the context of new technology (see also, Foucault, 1975, 1977; Latour, 1993, 1996). ${ }^{1}$

Sotto (1997) has asked such a question in his discussion on the effect of information technology for the possibility of organizational agency. Although Sotto does not set out to theorize the relationship between information technology and the constitution of subjectivity and identity, he successfully demonstrates that the insertion of information technology into the context of the organization - via a doubling of representation and the production of illusory spaces - gives birth to a new type of organizational actor: the playful (“ludicrous”) worker. As he puts it (Sotto, 1997, p. 37),”...informatics possesses a mode of representation of its own and this mode of representation affects whatever it absorbs.” Increasingly, information technology absorbs consumers, affecting how they 
are configured as "customers" by organizations, and how organizations relate to the customers thus produced.

Our question, then, is: what ideological and cultural work does information technology do in organizations? At the center of our discussion are computerized customer databases. Approaching information technology from a poststructuralist perspective, we call attention to the discursive effects of databases in Foucault's sense. Foucault's understanding of discourse and language is of special relevance for our study because of the relation he draws between language and the constitution of the subject. Mainly drawing from his genealogical work on the birth of such institutions like the clinic, the prisons, and sexuality, Foucault $(1975,1977,1978)$ develops a theory of the human being as a subject that is configured, and given cultural significance, in the first instance through language (see also Poster, 1995). In this view, a new language introduces a new way of constituting cultural objects (such as human beings and customers) and human relationships (such as markets). Computerized databases constitute such a new language and its introduction has changed the organizational language for understanding the market in general and customers in particular. Through organizational practice the customer emerges as a unique data representation or data profile that can be managed and targeted while the organization becomes the location where customers are configured as data-linguistic constructs, since it is organizations that hold the linguistic power of the database.

In this paper, we do not concern ourselves with the technical and computer-scientific aspects of databases and customer relationship management systems. Nor do we provide a managerial recipe for the successful implementation of such database-driven CRM ${ }^{2}$ 
systems in the organizational context. Our analysis is cultural; i.e. we start out with the assumption that organizations are cultural institutions that are located in a network of communication and meaning (cf. Fuchs, 2001). Our fundamental concern is with how such a cultural organization does its work. As a particular case in point we look at the cultural work organizations do with information technologies in the construction of customers. Hence we pursue three objectives. First, we provide a theoretical treatment of the customer database as discourse and illuminate what databases do when they are inserted into the context of organizational marketing management practices (e.g., in the form of CRM systems). Central to this discussion are a critique and an extension of dominant theories of virtual identity, particularly their assumption that a conscious subject is the author of his or her identity, even in virtual market spaces. This train of thought also requires us to retheorize the link between information technology and control (see Beniger, 1986). Second, we link our discussion about the discursive construction of the customer to the emergence of one-to-one relationship marketing as a powerful disciplinary paradigm. We argue that the “discursive work” databases do has played an important role in shaping and indeed limiting organizations' concept of customer relationship. Finally, we mobilize what could collectively be called theories of playful consumption to juxtapose the individualizing discourse of the database with the communal and theatrical spaces that can and do exist online (cf. Danet, RuedenbergWright, and Rosenbaum-Tamari, 1997; Geertz, 1973; Grayson, 1995; Holbrook, Chestnut, Oliva, and Greenleaf, 1984; Holt, 1995). By doing so, we hope to open up the current discourse on customer relationship management to include relationships among customers, between customers and non-customers, and between customers and the virtual 
organization. In particular we argue that "virtual play" (Aycock, 1993) offers consumers social spaces where identity is no longer so much inscribed on them than performed by them. In conclusion we suggest managerial implications of our reflections.

\section{Where we stand: Soft technological determinism}

Our argument is based on a theory of technology that aligns itself with a "soft" form technological determinism (see Smith and Marx, 1994). This view holds that changing technologies will always be only one factor among many others - including political, cultural, and economic ones - responsible for changing history, society, cultural representations, and economic processes among other things. Soft technological determinism thus overcomes the simplicity of "hard" technological determinism that proposes a simple cause-effect relationship between technological and historical change (MacKenzie and Wajcman, 1999). The key problem of hard technological determinism is its underlying assumption that technological change is an independent, almost metaphysical force that develops outside society and culture and continuously impacts both from "the outside.” Ample evidence exists to reject this theory by showing how technological development and adoption is highly contingent on the materialist conditions (in Marx's sense) of technological production and consumption. In other words, technology is socially shaped (Bijker, Hughes, and Pinch, 1987; Latour, 1996; Winner, 1977). However, as MacKenzie and Wajcman state (p. 4), "the failure of hard technological determinism does not rule out the possibility of a soft technological determinism" if we acknowledge that technological change can cause social and cultural change however complex and contingent it is on the same social and cultural forces it changes. Our position on technology also rejects the popular instrumental view of 
technology that upholds that technology is inherently value-free and neutral, i.e. its form, shape, use, and effects are driven by the need of the user (Feenberg, 1991). Compared to this view we are admittedly more deterministic, aligning ourselves with the tradition of “political technology” still most skillfully represented by Langdon Winner (1977, 1999). This position upholds that by adopting a technology we may be opting for a lot more in terms of social, political, economic, and cultural implications than appears at first sight. Thus, not all implications of a technological choice such as CRM are always a function of the decision maker's initial needs. Such a statement - in fact our entire argument - does not at all exclude the possibility that the adoption of databases or CRM also helps organizations fulfill certain objectives like getting a more complete view of their customers and a better understanding of customer needs and wants, which in turn leads to better targeted marketing (the need of the marketing manager). But limiting oneself to this instrumental perspective focuses analysis solely on how to adapt technology while our view stresses the aspect of how to shape technology and how technology shapes practice, society, and culture (cf. MacKenzie and Wajcman, 1999; see also Sotto, 1997). Thus our analysis of databases and CRM assumes that organizations adopt these technologies to improve certain specific business needs and while they may do so, they also do something else, something more. Discovering what that 'more' might be is at the heart of this paper.

\section{Databases, CRM, and the disciplining of human difference}

Customer relationship management is increasingly taking center-stage in organizations’

corporate strategies (Greenberg, 2002; Swift, 2001). CRM, closely related to notions of relationship and database marketing, aims at creating, developing, and enhancing 
personal and valuable relationships with customers by providing personalized and customized products and services (McKim, 2002; Rigby, Reichheld, and Schefter, 2002). For it to work, a CRM system relies on its ability to identify and interpret individual customer records. Underlying organizational CRM systems are massive customer databases. Fueled by the steady and steep decline in the cost of data storage and handling over the past thirty years, organizations invested in creating increasingly detailed profiles of their customers and non-customers, despite the fact that such information is not necessary for billing and service-delivery purposes. From bookstores to supermarkets to large chemical manufacturers, organizations make efforts to bestow individual customers with a unique and graspable identity (Fayyad and Uthurusamy, 2002; Roberts, 1999).

Along with the rise of database technologies and electronically mediated languages, new forms of institutional and organizational power have emerged (Beniger, 1986; Introna, 1997). Two camps, one with a libertarian and the other with a Marxist outlook, have been commenting most prominently on the implications of this new mode of information (Poster, 1990b). The libertarians are mostly concerned about the potential centralization of surveillance power in the hands of state and commercial institutions. In this view, database technology and networked communications are regarded as additional components of the always-growing threat of overbearing government and ever-more intrusive corporations (Cate, 1997; Cavoukian and Tapscott, 1997; DeCew, 1997; Marx, 1988). Marxists are more concerned with the contribution of computer networks and database technology to the dominance of corporations over the working class. Since information is not available to all on an equal basis, this camp maintains that capitalists 
can seize information technologies to further monopolize control over the means of production (Schiller, 1992, 1996).

Both viewpoints have much to offer for our understanding of the impact of information technology on social and economic structures in the networked society. However, they fail to grasp the cultural innovations brought about by the integration of information technologies like databases into existing political, economic, and social institutions (Poster, 1990b, 1995; Sotto, 1997). The problem of information technology's cultural effects escapes Marxists and liberals because they theorize the social field primarily as one of action, “minimizing the importance of language” (Poster, 1995, p. 79). Yet, databases are made up of symbols in data fields. They embody a specific mode of representing the world, what Bolter (2001b) calls numeric inscription. As Poster (1995) puts it, "one does not eat them, handle them, or kick them, at least one hopes not. Databases are configurations of language; the theoretical stance that engages them must take at least this ontological fact into account” (see also, Sotto, 1997).

In light of these comments we would like to ask what differentiates the language of the customer database, which is still new and emerging, from those discourses on the customer that preceded it and how these differences link up with other organizational strategies such as the formulation of customer relationships. We propose that the emergence of customer relationship management as discourse is premised on the database's power to individualize the consumer. The formation of sizeable, identifiable, and searchable customer data profiles makes possible their codification, classification, and comparison. Foucault writes in Discipline and Punish (1977, pp. 191-192): 
For a long time ordinary individuality - the everyday individuality of everybody remained below the threshold of description. To be looked at, observed, described in detail, followed from day to day by an uninterrupted writing was a privilege....The disciplining methods (such as medicine, psychology, criminology, pedagogy) reversed this relation, lowered the threshold of describable individuality and made of this description a means of control and a method of domination. It is no longer a document for future memory but a document for possible use. ... This turning of real lives into writing [...] functions as a procedure of objectification and subjectification.

Unlike the delinquent, the mentally ill, the sick person, and the child who have been the objects of discourses of individualization for a long time, the consumer had not been subjected to a permanent and ubiquitous regime of surveillance and observation before the arrival of the electronic database and the widespread use of electronic and digital transaction formats in the marketplace.

This is not to say that consumers remained unobserved before the arrival of electronic databases and networked communication. Historically, marketing emerged as a practice only when production capacities surpassed demand and the need to control consumption became a chief concern for producers (Baudrillard, 1988; Sawchuck, 1994). Hence, from its beginnings marketing was conceived as an applied social technology designed to manipulate consumer decision making (Schroter, 1997). Competition for consumers' preferences elevated advertising to marketing's most promising weapon. Yet, as Beniger (1986, p. 20) points out, “[W]ith the development of mass communication by the turn of the century came what might be called mass feedback technologies.” In 1931 Percival 
White, a pioneer in market research development, introduced to the field the concept of measuring markets and researching consumers (Bartels, 1988). By the end of the decade, professional market research was a firmly established discipline and obtaining market feedback was considered crucial for business success. However, these early forms of market research were driven by economic considerations of the firm and more specifically the need to forecast aggregate consumption for improved planning of manufacturing output (Beniger, 1986). During the 1950s psychologists like Ernst Dichter and George Katona and sociologists like Paul Larzarsfeld and Pierre Martineau entered the marketing research fray and shifted the focus from "who" and "what" to "why" people bought, opening the door to the possibility of identifying greater diversity of consumers' behavior, attitudes, and motivations (Cohen, 2003). The fiction of the unified mass market was quickly demolished and a new system of marketing knowledge emerged that was based on classifying consumers according to a set of different motivations and priorities (Miller and Rose, 1997). Market segmentation was born and continuously refined through the introduction of psychographics in the 1970s (a technique that combines demographic and psychological factors) and geodemographics in the 1980s (a technique that allows the mapping of certain demographic and psychographic clusters in geographic space—a key driver of increasingly targeted direct marketing campaigns [Goss, 1995]). Yet, while market research techniques matured resulting in the ability to identify smaller and more homogeneous consumer segments, any further progress towards total customer identification was limited by the comparatively slow, unspecific, and non-interactive nature of market feedback technologies. 
A 1993 cartoon in The New Yorker ${ }^{3}$ beautifully illustrates both the potential power as well as the shortcomings of these new market research techniques. At a cocktail party in a presumably upper-middle class, suburban home, a middle-aged man is shown sitting on a sofa next to a woman drinking wine. He says to her: 'According to my zip code, I prefer non-spicy foods, enjoy tennis more than golf, subscribe to at least one news-oriented periodical, own between thirty and thirty-five ties, never buy lemon-scented products, and have a power tool in my basement, but none of that is true.' The man's wry observation reveals that the customer representations created by these market research techniques are above the level of individual identification. His comment, however, also illustrates that by using increasingly sophisticated market feedback techniques including data from credit card transactions, census, coupons, and traditional customer surveys and the storage of such data in quickly growing electronic databases, market researchers at the end of the 1980s were able to identify very particular and small homogeneous subsegments within the market. In other words, the formula used to identify similarity and difference among consumers had grown very sophisticated and yet, it was still not capable to reach down to the level of the individual, resulting in mischaracterizations as expressed by the cartoon. So, while systems of customer differentiation and market knowledge existed before the convergence of electronic communication networks and the database (cf. Hacking, 1982, 1986), they were unable to make visible individual consumers. Only when abundant, interactive, and person-specific market feedback converged with the quickly growing power of the electronic database such microscopic acts of distinction became possible. The hitherto "massified” consumer who remained epistemologically absent while anonymously slipping in and out of markets can now be 
inscribed, recorded, and classified according to attributes, capacities, and conducts and finally differentiated against other individual data profiles. This is the process of individualization that became possible only with the language of the database.

As the customer database spans an observational and perceptional surface along the dimensions of visibility and codeability that allows organizations to register individual conduct, a new type of customer emerges. He or she is no longer "lost in the fleeting passage of time, space, movement, and voice but identifiable and notable” (Rose, 1988). Within the regime of norms and requirements that make up this perceptual surface, one customer - encoded according to a clearly defined language of data fields and algorithms - can now be placed in relation to other customers. The database is the latest incarnation of Foucault’s Panopticon, “this enclosed, segmented space, observed at every point, in which individuals are inserted in a fixed place, in which the slightest movements are supervised, in which all events are recorded, in which an uninterrupted work of writing links the center and periphery [...], in which each individual is constantly located, examined, and distributed among the living beings” (Foucault, 1977, p. 197). In the final analysis, the electronic and digital transaction space between organizations and their customers becomes a map that enables the emergence of what was previously imperceptible and below the threshold of description: the individual customer. As philosophers of sciences, language, and media have pointed out, (e.g., Baudrillard, 1994; Foucault, 1972; Habermas, 1984; Ian Hacking, 1983; Ong, 1982), new systems of representation - be it writing, statistics, or digital information flows - articulate newly ordered spaces of knowledge. In accordance with the database's law of representation we can say that when the object of representation (i.e. the customer) becomes observable, 
measurable, and quantifiable, it becomes known. Hence the database not only individualizes the customer, it also constitutes the customers as a known and knowable object upon which the organization can act strategically. For the first time in history organizations, institutions, and the state are enabled to survey, observe, and individualize very large populations in very short amounts of time. This is the fundamental logic of what we call the Age of Total Marketing where the threshold of detecting ordinary individuality has been lowered to such a degree that the individual consumer emerges as an epistemological entity. Therefore, it might be useful to think about the mode of functioning of the customer database as a representational or discursive machine that identifies and harnesses human difference (cf. Rose, 1988).

\section{Virtual identity revisited}

Because the database virtualizes the customer and by extension the relationship between the customer and the "virtualizing" organization, the discourse of the database raises hitherto overlooked questions about virtual consumer identity. The study of virtual identity began in earnest only after the cultural and social impacts of the Internet began to become apparent toward the end of last decade and therefore has strongly been influenced by the character and characteristics of this new medium. Effects of earlier information technologies such as databases that have been at the center of the digital revolution remain largely underanalyzed from a cultural and social perspective.

Within the discourse of the Internet and virtual reality (VR), efforts to theorize the construction of identity in virtual environments have revolved around two opposite poles made up by what we refer to as the "disembodied” and the "embodied" camps. The disembodied camp argues that in the virtual world of cyberspace the human body has lost 
its relevance as the site where identity is constructed (Balsamo, 2000; Stone, 2000;

Turkle, 1995). Evoking postmodern conceptions of identity where the self is never fixed but fluid and multiple, such theories focus on the playful and theatrical aspects of textbased cyber-identities (cf. Laurel, 1991; Turkle, 1995). Like protagonist Case in William Gibson’s (1984) original cyberpunk novel Neuromancer, individuals who "jack into" the matrix (e.g., MUDs, MOOs, and chat rooms) leave the limitations of the physical body behind and perform versions of themselves purely by virtue of their cognitive prowess. Thus, theories of disembodied identity understand the virtual realm as a theater of discursively performed identities, a space for "identity tourism", where to be a tourist is to possess mobility, access, and creativity to enact different roles at different places (Nakamura, 2002).

Theories of embodied virtuality reject the notion of a purely cognitive subject that can escape the body while constructing multiple identities in cyberspace (Hayles, 1999; Mingers, 2001). Adopting a theoretical stance that has its origins in Merleau-Ponty's (1962) phenomenology of perception, proponents of this camp suggest that the split between mind and body never really took place even as the body became immobilized in front of a computer screen and a virtual representation of the individual began acting as an agent in computer-mediated environments (see for example, Dreyfus, 1992, 2001; Heim, 1993; Robey, Schwaig, and Jins 2003). John Mingers (2001) argues strongly against the disappearance of the body in the discursiveness of information systems. He suggests that the embodied nature of cognition cannot be ignored in any attempt to theorize virtual identities. He bolsters the development of his anti-Cartesian theory with evidence from research in group decision support systems (GDSS), concluding that 
virtuality only allows for a reduced and incomplete construction and representation of identity (see also, Dreyfus, 2001). In Mingers’ final analysis virtual disembodiment robs the actor of the benefits and richness of a host of tacit, habitual, and subconscious forms of knowledge because these forms of "knowing" are inextricably tied to corporeal experience and action (see also, Berthelot, 1986; Bourdieu, 1977, 1990; Shilling, 1993).

Within the confines of this essay, we do not intend to resolve this interesting and heated debate. Rather, we would like to add to the already existing complexity of the issue by bringing to the table a perspective that questions the assumption implicit in both paradigms of the individual as a rational, conscious, and autonomous actor who remains, whether embodied or not, the author of his or her own identity in virtual environments. As we do so it is not our aim to suggest that individual agency simply vanishes in the digital spaces of the Internet, GDSS, or the customer database. Nor do we want to "theorize away" the possibility for empowerment in virtual environments. Both individual agency ${ }^{4}$ and empowerment (e.g., of organizations, workers, citizens, and consumers) remain important features of new interactive communication and information systems. Yet, it is clear that the effects of new information and communication technologies on user agency and empowerment never cut just one way; they are always ambiguous and contradictory, contesting and overthrowing old hierarchies of power and knowledge and creating new ones (Breen, 1997; Kling and Allen, 1996; Metha and Darier, 1998; Mumford, 1967; Ong, 1982; Virilio, 2000).

Database technology is no different. An organization that sets up large and sophisticated data warehousing systems and connect dispersed databases - even inter-organizationally, as in the case of airlines for example - gains a panoptic view of each individual customer. 
The identification of a customer as, say, "loyal”, "not loyal”, or something inbetween these two categories depends on both the organization's ability to see each customer individually and on the regime of norms and requirements that make up the organization's perceptual surface on which each customer will be mapped based on his or her individual conduct. In other words, loyalty becomes a function of visibility and codeability of customer behavior. Both operations are in the hands of the organization, resulting in the production of virtual representations of real customers. In fact, given the fragmentation and dispersion of such customer databases within and among organizations, multiple and divergent facsimiles per consumer are produced and acted upon by the organization (Poster, 1990a). At this particular moment,, identity always mediated by language is no longer uttered and constructed by an autonomous actor but authored by the organization. In the final analysis, the customer database produces a form of virtuality where the consumer subject is no longer the site of identity construction but its object.

This, then, is the world of CRM at the speed of light (Greenberg, 2002), where "in effect these electronic lists become additional social identities as each individual is constituted for the computer, depending on the database in question, as a social agent" (Poster, 1995, pp. 87-88, italics added). The mixing and matching of data fields and categories leads to the construction, deconstruction, and reconstruction of customer profiles according to the knowledge needs of the marketer. Most databases fail to refer back to their objects of representation (the consumers) to improve accuracy. ${ }^{5}$ Databases, thus, can and do construct a multitude of representations of one and the same consumer. If a consumer is captured in two distinct databases that differ in composition and content of 
their data fields, that consumer takes on two personas, two identities in the marketplace. Both databases define him or her differently as consumer subject for any agency or business that has access to these databases. In fact, within the rules of the database it is no longer accurate to speak of the consumer. The consumer becomes a blended digital simulation whose "nature" depends on the composition of the databases. ${ }^{6}$ There are now as many identities per "real" consumer as there are database representations of her. The real power of CRM and database marketing is not to get as close as possible to the customer but to discursively create her.

The database plays an integral role in the production and continuous expansion of language that structures how we know the customer. It is helpful to remind ourselves that databases on a basic level are made up of "data fields" containing information on individuals’ names, postal code, sex and whatever else might be obtained (Goss, 1995). Carefully combined fields constitute an individual "record" and several of those compose a list. In a digitalized format, such lists are transferable, exchangeable, and comparable to other lists. Databases have grown increasingly complex and large online retailers such as Amazon.com, Inc. are no longer satisfied with and limited to geodemographic information. For a successful data mining initiative, the value of data is in the details (Berry and Linoff, 2000; Rud, 2001). In the Internet age, a solid customer database not only contains customer contact and purchase information but "intensive customer intelligence" - historical buying and search habits as well as real-time clickstream information - allowing for interactive predictive modeling of customer preferences (Vriens and Grigsby, 2001). Along the way, individual customer data sets have grown from a "low dimensional" format, consisting of less than ten customer variables, to a 
"high dimensional" format where one customer record may consist of tens of thousands of data fields (Fayyad, 2001).

Researchers and practitioners in the field speak of "mining” data, "discovering” knowledge, and “identifying” structures (Brachman, Khabaza, Kloesgen, PiatetskyShapiro, and Simoudis, 1996; Fayyad, 2001; Fayyad, Piatetsky-Shapiro, and Smyth, 1996), revealing a view of data as a rich and objective source of knowledge. In addition, Brachman et al. (1996, p. 44) employ traditional hermeneutic language when they state that a "realistic knowledge discovery process is [...] not simple and linear, but thoroughly iterative and interactive.” Usama Fayyad (2001, p. 64), one of the foremost thinkers in the field of data mining and knowledge discovery, refers to data as "latent information" that reveals itself only if modeled and analyzed correctly. This argument rests on the claim that the sheer complexity of high-dimensional customer data prevents simple human perception form discerning the meaning hidden therein. Therefore turning data into knowledge, “precisely data mining’s goal” (Fayyad, 2001, p. 64), depends on the analytical power of technologies such as the Management Discovery Tool (MDT) system, developed by NCR and ATT, or Lucent Technology's NicheWorks. The promise of these analytical tools is to "allow business users to interact directly with data" (Brachman et al., 1996, p. 45).

It is precisely this interaction with the data that is widely mischaracterized as a process of simple (or not so simple) discovery and extraction of knowledge, when in fact it must be understood as an act of constituting the customer and indeed the larger market reality. Apte et al. (2002, p. 50), discussing the process of identifying customer segments state that, "good segmentations tend to be obtained only through trial and error by varying the 
segmentation criteria.” For this process, using “domain knowledge, simple heuristics, and clustering algorithms”, data is partitioned, sliced, diced, and pivoted, finally reduced and filtered (Apte et al., 2002; Jackson, 2002). In a second step, tools such as IMACS and Clemenine are used to support the knowledge discovery process and to simplify the embedding of discovered knowledge into an application the business user can use including the production of customer definitions (Brachman et al., 1996, see also Loveman, 2003).

To ignore the statistical, mathematical, and linguistic labor that goes into the data mining process and to call it a "simple exploration of the data through passive techniques" (Brachman et al., 1996, p. 44) neglects the role of the data miner in the construction of the customer she proclaims to discover. As databases grow in number and size at blistering speed, the location of identity construction is no longer to be found in the atomic physics of the market but "the digital physics” of data banks (Fayyad, 2001). There, the consumer's identity is multiplied and distributed through the network of electronic communication, elevating the digital simulation of the customer to the status of the ontologically real (cf. Baudrillard, 1994; Brown, 1995).

From a poststructuralist perspective it is therefore not completely accurate to speak of CRM and database marketing as technologies of customer addressability (Chen and Iyer, 2002). Databases are first and foremost technologies of customer construction. They inscribe personalities and identities onto consumers according to their discursive rules of formation, specifying the system according to which different kinds of consumers are divided, contrasted, related, regrouped, classified, and derived from one another as objects of organizational and marketing discourse. To put it in Foucault's terms (1972, p. 
55), "[T]hus conceived, discourse is not the majestically unfolding manifestation of a thinking, knowing, speaking subject, but, on the contrary, a totality, in which the dispersion of the subject and his discontinuity with himself may be determined.” In other words, recognizing how the database is formed by many hands and populated with data from many sources forces us to depart from the romantic notion of the autonomous and unified consumer subject who, by virtue of rational consumption acts and conscious speech acts, constructs his own identity in the computer-mediated marketplace (Firat and Venkatesh, 1995).

Within our discussion, Beniger's (1986) concept of the control revolution takes on an additional meaning. In his important book, Beniger contextualizes the increase of information and communication technologies during the $19^{\text {th }}$ and $20^{\text {th }}$ century within radical societal transformations. His analysis shows that the rise of the information society was the result of the economic and business crisis created by the industrial revolution. The increase in velocity, complexity, and volume of industrial processes required new means of social control. Large-scale technological information and communication systems such as the telegraph, bureaucracies, accounting, and of course computers provided this control. Hence, in Beniger's view the development and implementation of information and communication technologies - and thus the rise of the Information Society - are first and foremost driven by a will to control processes, populations, resources, and data (see also Castells, 1996; 1998).

What Beniger implies throughout his study but never awards the centrality it deserves is the fact that in his model controlling is a function of seeing. Bureaucracies, computers, and accounting techniques are first and foremost, paraphrasing Virilio (1994), vision 
machines. In this respect, Beniger's concept of control is theoretically contained in our model of the database as discursive machine that provides the organization with total visibility of the field of consumption. Market feedback, for example, is now received by the organization in seamless and detailed data flows allowing for individualized marketing communication mixes and accurate evaluation of these personalized messages for their effectiveness to produce the desired behavior (Allard et al., 1999; Mulvenna, Anand, and Buchner, 2000). As new information and communication technologies deliver interactivity and real-time feedback capabilities, marketing control in Beniger’s sense has grown tighter. But the organization gains another form of control that Beniger's model cannot recognize because it assumes an ontological separation between the object of control and the technology of control. In other words, Beniger theorizes technology as a force that governs the individual from the outside by affecting its behavior all the while leaving it ontologically unchanged.

Beniger thus remains blind to the constitutive power of control technologies, which we suggest marks the latest incarnation of the control revolution. Databases may now represent the most powerful aspect of control technologies. ${ }^{7}$ They radicalize the concept of control because of their ability to constitute the object they help control. Put differently, our model of the database as control technology suggests a doubling of control manifested in the ontological constitution of the object of control.

It is true that consumers participate in the formation and population of their own data record by committing simple consumption acts. The formation of digital consumer identities, however, takes place without the presence of the consumer subject. In fact, with improving online tracking and recoding technologies improving and the increasing 
selling and exchanging of customer records, the consumer is no longer able to decide what kind of information about her is stored, categorized, manipulated, exchanged, and acted upon by whom, when, and where. "Unlike spoken language, the database is not only remote from any authorial presence but is 'authored' by so many hands that it makes a mockery of the principle of the author as authority” (Poster, 1995, p. 85). Therefore information technologies such as databases challenge the theory of virtual identity by radicalizing the concept of identity construction as a conscious act of a "material", rational agent.

To summarize, the introduction of information technologies such as customer databases into the organizational fabric produces a new form of consumer: the individualized customer. This act of consumer individualization - based on the workings of the database - transforms the ways in which inscriptions of human individuality can be produced, ordered, accumulated, and circulated (cf. Rose, 1988). In its essence, database-driven information technologies "provide a technique of visualization and inscription of individuality which objectifies its subjects by inscribing their differences from one another” (Rose, 1988, p. 195). Such developments in the ways in which descriptions of consumers are created, ordered, organized, and acted upon do more than facilitate storage, communication, and analysis of information. They become important discursive acts that configure a human being as a consumer subject by inscribing difference. From a poststructuralist perspective the customer database bestows the organization with the linguistic power to produce fixed, closed, and stable consumer identities and to make them culturally significant, i.e. to strategically act upon these identities. Databases and related information technology thus become relevant for a theory of virtual identity 
because of the way these technologies challenge the assumption - implicit in the dominant theoretical camps of this debate - that the construction of identity in virtual spaces originates with a conscious and "cognitively present" ${ }^{8}$ actor. We argue instead that the proliferation of data warehouses, the creation of detailed customer profiles, and the implementation of complex analytical methods for data mining, has given rise to a new language that constitutes subjects outside the immediacy of consciousness and in absence of the "material" consumer.

\section{Inventing the one-to-one relationship}

The panoptic regime of the database has affected managerial and theoretical debates in marketing. Beginning in the late 1980s and gaining steam throughout the 1990s, a discourse emerged that promoted close, intimate, one-to-one relationships with the customer as the path to marketing nirvana (Allen, Kania, and Yaeckel, 1998; Peppers and Rogers, 1993, 1997). Replacing a more sales and transaction-oriented concept, relationship marketing has since become the dominant paradigm in practitioner-oriented and academic marketing discourse (e.g., Grönroos, 1995; McConnell and Huba, 2003; O'Dell and Pajunen, 1997; Payne, 1995; Vavra, 1992). As Addis and Holbrook (2001) state, "relationship marketing emphasizes the role of the relationship between a vendor and its customer, with particular reference to the importance of personal involvement and trust." Hence, one of the key goals of this new strategy is to position the company as a trusted advisor capable of providing relevant messages that keep the customer involved with the brand. The stated goal of relationship marketing is building customer equity through customer retention and maximization of customer lifetime value for the organization (Blattberg, Getz, and Thomas, 2001). Underlying this marketing paradigm is 
the ability of the organization to identify and continuously track each individual customer, a process that eventually represents a form of "customer branding."9

Customer branding, of course, is closely related to the concept of the individualized customer presented here. Both are based on the language of the database which produces sizeable, identifiable, and searchable customer data profiles and enables codification, classification, and comparison of minute individual differences in human conduct (Blattberg, Glazer, and Little, 1994). The transparency provided by the database includes, among other things, the customer's contribution to revenue and the cost to serve that customer. It becomes therefore possible to identify for each customer his or her exact net contribution to the organization's bottom line. A thus-individualized customer base is the ultimate objective of database marketing practice because it is now possible to aim concrete strategic marketing decisions at digital customer identities including adding or removing product benefits and service privileges, pricing and promotion.

The one-to-one marketing paradigm justifiably has received praise in the literature for its ability to increase profitability and provide added value to customers through personalization and customization. Falling costs for communication and data storage technology as well as the rise of the Internet have accelerated organizations’ adoption of increasingly complex relationship tools. While the early hype surrounding the implementation of CRM systems has somewhat abated and been replaced by more reasonable expectations of their technological feasibility and short-term managerial benefits (Farrell, 2003), companies are aware that their operational systems contain mountains of untapped knowledge about their customers' preferences, buying habits, life events, and expectations that could be integrated, mined, and interpreted (Brachman et 
al., 1996; Fayyad, 2001; Fayyad and Uthurusamy, 1996). Digital marketspaces in particular have accelerated the gathering and storing of detailed customer data and given rise to more web-based strategies of customer interaction and relationship marketing (Allen, Kania, and Yaeckel, 1998; Sterne, 2001). However, these strategies are strongly biased towards dyadic forms of communication and relationship with the organization on one side and the individualized consumer on the other (see e.g., Allen, Kania, and Yaeckel, 1998).

We argue that the individualizing effect of panoptic information technologies has produced the dominant discourse of one-to-one relationship marketing to the exclusion of other possibilities of customer relationships. While this model was effective before the Internet, we suggest that virtual marketspaces have introduced possibilities for new types of relationships requiring a reconceptualization of our current understanding of customer relationship marketing and management, if organizations are to really leverage their power. Of course, we do not suggest that one-to-one customer relationships are obsolete or wrong. They continue to play a critical role in an organization's efforts to stay competitive. What we are proposing is that the nature of virtual spaces allows for additional types of relationships and that these relationships, if developed and managed correctly, add value to both the customer and the organization. Below we explore theories of play from the fields of consumer research and computer-human interaction as one possible avenue that could help us open up the monolithic discourse on customer relationship management with its traditional focus on the company-customer dyad.

\section{IT and the theory of playful relationship spaces}


In the final part of the paper we turn our attention to the notion of playful consumption to formulate a more complex model of relationship management. We conceptually connect virtuality (or what Sotto [1997] calls “information technology simulation”) and consumption to "play" in order to build a theoretical space in which consumers can be conceptualized as actors who perform their own idea of identity and relationship with each other and the organization. To be sure, the specter of organizational discourse that individualizes and inscribes consumers does not disappear in our theory of playful relationship space. In marketspaces that are governed by the language of the database consumers cannot escape their constitution as objects of knowledge and analysis. The space of play that we want to introduce as a possibility here is phenomenological and therefore is neither absolute nor structurally subversive. In fact we warn against overusing the play metaphor or endowing it with revolutionary and liberatory powers that it cannot have. Already in the concluding years of the 20th century, there were many signs of normalization and institutionalization and processes that curtail the carnivalesque flavor of virtual spaces in many contexts such as work and consumption. Yet, Sotto's argument that information technology simulations, even in normatively highly bounded spaces like collaborative work environments, provide a space for playfulness among its participants is encouraging. The possibility for play is rooted in the ontological transformation of the participating subject into a semiotic representation whose malleability and discursive openness is conducive for experimentation, albeit within limits. Play nevertheless carries the promise of what we call "weak agency" by providing consumers with a (if perhaps illusory) performative moment in the panoptic space of digital marketspaces (Dholakia and Zwick, 2001; Zwick and Dholakia, forthcoming). 
The relationship between play and virtuality has been explored before. Danet, Ruedenberg-Wright, and Rosenbaum-Tamari (1997, p. 41) argue that “computermediated communication is strikingly playful” and Sotto (1997) suggests that action and performance in virtual, simulated spaces is likely to lose its responsible character making room for the "ludicrous", playful, and illusory in human behavior. Drawing from Huizinga’s (1950) cultural anthropology of play and echoing in many ways Paul Virilio’s (1989) theory of perception, Sotto maintains that the “...'play element' involved in the realm of virtuality clearly appears as an inherent quality of that reality” (p. 49). He points out that increasing levels of abstraction in a culture lead to the development and use of metaphoric representations, which are nothing other than play upon words. Such a form of play is voluntary and therefore artificial (as opposed to naturally necessary for survival). In addition, as Caillois (1979, p. 19) states, "all play presupposes the temporary acceptance, if not of an illusion (indeed this last word means nothing less than beginning a game: in-lusio), then at least of a closed, conventional, and, in certain respects, imaginary universe. Play can consist not only of deploying actions or submitting to one's fate in an imaginary milieu, but of becoming an illusory character oneself, and of so behaving.”

Virtual spaces such as Internet Relay Chat (IRC), Instant Messaging (IM), Computer Supported Collaborative Environments (CSCE), and bulletin and discussion boards seem capable of encouraging the "ludicrous dimensions" (Sotto, 1997, p. 45) of play by linking playful behavior and virtual space on an ontological level. In other words, while simply participating in IRC, IM, or CSCEs does not in any deterministic way cause playful behavior, these spaces provide a structure that is conducive to play. Hence, information 
technology simulations may at any time become product and producer of play and playful behavior.

Four interrelated features of information technology simulations encourage virtual play (Aycock, 1993): ephemerality, speed, interactivity, and freedom from physical restrictions (Danet et al., 1997). As studies in human-computer interaction have shown (e.g., Bolter, 2001b; Delany and Landow, 1991; Lanham, 1993; Laurel, 1991; Turkle, 1995), the eminence and performance of play increases as we move from basic wordprocessing of author-absent texts to more interactive and synchronous communication. In its extreme forms of fast-paced, interactive computer-mediated communication, the interaction is experienced as something akin to a video game (Heim, 1987; Turkle, 1995). Playfulness may be driven by the engrossing flow experience that synchronous modes of online communication engender among participants because of the enchanting quality of instantaneity in interaction with computers (cf. Csikszentmihalyi, 1997; Hoffman and Novak, 1996). Feedback prompts feedback and - just like during play - people lose all sense of time and space, suddenly awakening to the fact that hours have passed. Thus, the possibility of playfulness in information technology simulation, what could be called information technology illusion, is derived from the interactive relationships that form among participants of the illusion.

Speed and interactivity are key features that contribute to making computer-mediated environments prime locations for the enactment of playful consumption. Holt (1995) suggests that "consuming as play" is an important metaphor to describe consumer behavior. Similar to the consumer theories outlined previously, Holt (1995, p. 9) maintains that "consuming not only involves directly engaging with consumption objects 
but also includes using consumption objects as resources to interact with fellow consumers. ${ }^{10}$ Playful consumers pursue actions for their propensity to enhance the interaction among the game's participants. Thus, interaction becomes an end in itself, thereby stressing the non-instrumental character of playful consumption. The noninstrumental, what Holbrook calls the autotelic (1984) character of playful consumption, becomes its defining moment against non-playful consumer behavior.

Instructive for our purpose is Holt's differentiation between communing play and socializing play. Communing play captures the shared lived experience of consumers around the object of consumption. Playful consumption then gives birth to a collective consciousness, which for the duration of the game suppresses the participants' social, cultural, and economic differences and accentuates - within the structures of the rules of the game - their singular most important aspect of mutual identity (see also, Birrell, 1981). Communing play leads to the formation of what could be called "consumption teams.”

Socializing play, conceptually closely related to communing play, allows the players to engage in performative, almost competitive acts of interaction. Among players who are very well versed in "the rules of the game" (Pierre Bourdieu) reciprocal exchanges materialize where one dialogues against/with another in shared delight. While instrumentality might be missing from the exchange, socialization is in fact completed and the result is a game for recognition and status. ${ }^{11}$

Playful consumption takes place in "sacred" places: the stadium, the mall, the play table, the flea market, the magic circle, the temple, the stage, the film screen, the courtroom, and the computer screen. These are all in form and function playgrounds just like 
Disneyland (Grayson, 1995) or Wall Street (cf. Gordon, 1999; Huizinga, 1950; Keynes, 1964). Playgrounds are hallowed places, removed, fenced in, and consecrated, in which unique rules apply. In the marketing literature, John Deighton (1992) used the concept of performance to stress the inherently dramaturgic character of playful consumption, suggesting that the marketer can influence the social context within which consumers are encouraged to perform. Somewhat overly structuralist in his account of consumer response and behavior, Deighton nevertheless usefully points to the central role of marketers as both the architects and directors of "theaters of consumption" (see also, Firat and Dholakia, 1998). Consumers, from this perspective behave "as if they were audiences responding to or participating in performances” (Deighton, 1992, p. 362).

Investigations that look at how computer-mediated environments affect the playful character of consumption are just beginning to emerge and further research is needed to illuminate the exact nature of this phenomenon. However as discussed above, the defining features of online environments should reinforce the possibility for playful consumption. Because "consumption becomes pathological when void of playfulness" (Campbell, 1987, p. 201), marketers should present consumers with the opportunity to experience exchange relationships as play (cf. Holt, 1995) by offering interactive and fast-paced conversational spaces (Berthon, Holbrook, and Hulbert, 2000; Levine, 2000). It is here where consumers can experience interrelated yet analytically distinct types of play such as play with identity or play with typographic symbols. ${ }^{12}$ In particular the ability of consumers to author their own identities, even perform multiple identities (Turkle, 1995) by developing nicknames and respective fantasy biographies, presents consumers in information technology simulations with a sense of empowerment and 
control that has been severely curtailed by the panoptic technologies of individualization (Dholakia and Zwick, 2001). Purposefully invoking an analogy to Sotto’s (1997) ontological approach to information technology, we argue that playful consumption spaces open up possibilities to consumers for reclaiming and reconfiguring a sense of agency. Playful consumption, in company-generated information technology simulations, then becomes the antidote to the panopticon of the customer database.

We do not suggest that play happens automatically every time marketers provide consumers with the opportunity to commune, socialize, and collaborate in virtual environments or that all communication and interaction that takes place in ludicrous spaces is always playful. The metaphor of play as it is used here simply proposes a form of being that is less governed by the limitations and guidelines of the physical world and more by the semiotic flexibility of virtuality. We are willing to accept that what we have in mind when we speak of play is not a universal category. To us more important than arriving at a global accord over the exact meaning of virtual play is to show that such behavior can produce a phenomenological sense of agency and to offer new conceptualizations of customer relationships.

If organizations are able to provide consumers with these spaces of communal and social play while placing them within the organizational marketing structure, they will be able to facilitate and benefit from a whole host of new customer relationships currently largely ignored including relationships among customers, between customers and non-customers, and between customers and the virtual representation of the organization. Research on virtual communities teaches us that the effects of communal and socializing types of play is likely to generate multilayered and complex customer relationships that foster 
compliance to and internalization of certain group norms as well as the development of a social form of identity (Bagozzi, 2000). What that means for marketing managers considering the opportunities of information technology simulation spaces such as the organizational website is clear. Allowing customers to play on the company's site and around the company brand reduces customer service costs, customer acquisition and retention costs, and costs resulting from product flaws and marketing mistakes. By the same token, improvements in customer segmentation and customization, brand commitment, customer satisfaction, and customer communications are likely, all of which are important qualitative relationship metrics.

\section{By way of conclusion: The managerial imperative of playful CRM}

We have presented a theoretical challenge to the concept of customer relationship management that is currently dominated by technological instrumentalism and one-to-one marketing. We argued that the historical roots of CRM in database technology led organizations to discursively construct customer relationships as a dyadic affair with the company on one side and the unique and individualized customer on the other. We argued that this conceptualization of customer relationships is a very limited one and that the advent of the Internet should encourage organizations to include hitherto marginal and unmanaged types of relationships To build our case for a more enriched and "polyadic" type of customer relationship - which includes the possibility for consumers

to interact with each other and with non-consumers, as well as a virtual representation of the organization - we tied together the possibility for play in virtual spaces with the playfulness of consumption. Where both intersect, customers experience a sense of empowerment, agency, and belonging. And it is here that organizations can create deep 
customer relationships, if, and only if, they are willing to discursively open up their current paradigm. Benefits will accrue for all participants (see Figure 1).

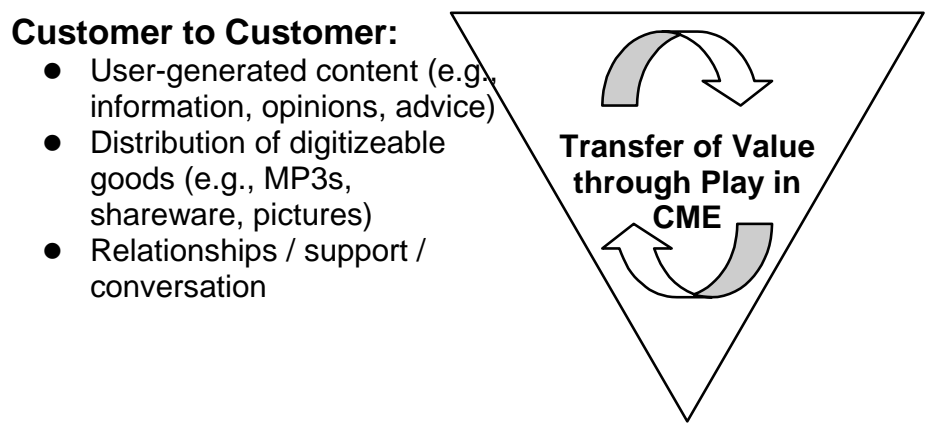

Organization to Customer:

- Provision of space for play

- Company-generated content / proprietary content (e.g., articles, editorials)

- Supervised chats (e.g., chats featuring guest Q\&A)

- Offline events (e.g., parties for members within geographic proximity)

\section{Customer to Organization:}

- Subscription fees

- Sales support to acquire noncustomers

- Fees to engage in an activity (e.g., online video-tutorials, participation)

- Commission fees (e.g., for goods sold in the space)

- Increased value for selling online advertising space

Figure 1: Examples of types of value created and shared through play

Database technology still plays a critical role in this endeavor because the need to individualize the consumer does not disappear. In fact, these new communal spaces do not protect the consumer from the panoptic gaze of the organization because free-flowing conversations can also be recorded, coded, and manipulated, thus adding to the discursive power of the organization. This ability, however, can be put to other uses besides opening up one-to-one relationships. Banks, for example, are among the most advanced relationship builders because of the tremendous amount of detailed electronic customer 
information they hold. With their rich knowledge of customers’ life stage, assets, risk preferences, and so forth, banks are able to develop very personalized messages to sell customized products and services, potentially increasing customer satisfaction and loyalty. What banks do not do, however, is link up members who are alike according to a few distinct personality variables (e.g., age, income, and recent job switch) and therefore likely to have very similar financial (and even non-financial) questions. A new model of customer relationship management brings such a segment together, not unlike a community, within a company-managed information technology simulation where customers can ask questions, give answers, and share their personal experiences as they encounter bureaucratic hurdles and clear them. Such a "ludicrous" space can be open to non-customers and may even be populated, from time to time, by experts and guests from the organization. These communal and socializing types of play enhance the willingness of consumers to share their thoughts with others, including the organization, thus making these playful interactions tremendously rich from a research perspective (Dussart, 2001). At any rate, the creation of playful spaces where customers become performers of their own identities and create their own compelling content builds trust and credibility among other customers, non-customers, and the organization and keeps everyone coming back. It may be argued that interactions and relationships that emerge from such an environment are immeasurably more passionate and involved than a purely companydriven affair based solely on the exploitation of stored customer profiles.

Future research is called for in order to 1) better understand how the language of the database constitutes customers and markets, and 2) evaluate the quality and measure the profitability of polyadic customer relationship management. The authors currently 
conduct qualitative fieldwork with the objective of understanding how database marketers in organizations with CRM systems actually interact with this technology to develop new representations of the consumer and the market. We are interested in what forms of representations and relationships are encouraged and which ones are discouraged as marketers begin to adopt the language of the database to construct reality. Additional research is also needed on the demand side to understand consumer perceptions of technologically mediated relationships with organizations, be they onedimensional or multilayered as proposed here.

In the final analysis, our model is a call for using the power of panoptic technologies for developing creative forms of multilayered customer relationships from which both the organization and the customer benefit. The informational panopticon, in some sense, has to dissolve into a fast-moving game of catch. The history of individualizing relationship management has become a conceptual liability for progressive customer management in computer-mediated environments. Letting customers play might just be the formula of success in the $21^{\text {st }}$ century. 


\section{Bibliography}

Addis, M., and Holbrook, M. B. (2001). On the conceptual link between mass customization and experiential consumption: An explosion of subjectivity. Journal of Consumer Behaviour, 1(1), 50-66.

Allard, K., Graves, L., Gluck, M., May, M., and McAteer, S. (1999, August 19). Proactive Personalization, from http://www.ericaclark.com/article4.html

Allen, C., Kania, D., and Yaeckel, B. (1998). Internet world guide to one-to-one Web marketing, from http://www.netLibrary.com/urlapi.asp?action=summary\&v=1\&bookid=26227

Allen, C., Kania, D., and Yaeckel, B. (1998). Internet world guide to one-to-one Web marketing

Apte, C., Liu, B., Pednault, E., and Smyth, P. (2002). Business Applications of Data Mining. Communications of the ACM, 45(8), 49-53.

Aycock, A. (1993). Virtual Play: Baudrillard online. Electronic Journal of Virtual Culture [on-line], 1(7), Available: ftp://byrd.mu.wvnet.edu/pub/ejvc/Aycock.v1n7.

Bagozzi, R. P. (2000). On the concept of intentional social action in consumer behavior. Journal of Consumer Research, 27(3), 388-396.

Balsamo, A. (2000). The Virtual Body in Cyberspace. In D. Bell and B. M. Kennedy (Eds.), The cybercultures reader (pp. 489-503). London and New York: Routledge.

Bartels, R. (1988). The history of marketing thought. Columbus, OH: Publishing Horizons, Inc.

Baudrillard, J. (1988). Consumer Society. In M. Poster (Ed.), In Selected writings (pp. 29-56). Stanford, CA: Stanford University Press.

Baudrillard, J. (1994). Simulacra and Simulation. Ann Arbor, MI: The University of Michigan Press.

Beniger, J. R. (1986). The control revolution: Technological and economic origins of the information society. Cambridge, Mass.: Harvard University Press.

Berry, M. J. A., and Linoff, G. (2000). Mastering data mining: The art and science of customer relationship management. New York: Wiley.

Berthelot, J. M. (1986). Sociological Discourse and the Body. Theory, Culture, and Society, 3(3), 155-164.

Berthon, P., Holbrook, M. B., and Hulbert, J. M. (2000). Beyond Market Orientation: A Conceptualization of Market Evolution. Journal of Interactive Marketing, 14(3), 50-66.

Bijker, W. E., Hughes, T. P., and Pinch, T. J. (1987). The Social construction of technological systems: New directions in the sociology and history of technology. Cambridge, MA: MIT Press.

Birrell, S. (1981). Sport as Ritual: Interpretations from Durkheim to Goffman. Social Forces, 60(2), 355-376.

Blattberg, R. C., Getz, G., and Thomas, J. S. (2001). Customer equity: Building and managing relationships as valuable assets. Boston, Mass.: Harvard Business School Press. 
Blattberg, R. C., Glazer, R., and Little, J. D. C. (1994). The Marketing information revolution. Boston, Mass.: Harvard Business School Press.

Bolter, J. D. (2001a). Writing space : computers, hypertext, and the remediation of print (2nd ed.). Mahwah, N.J.: Lawrence Erlbaum Associates.

Bolter, J. D. (2001b). Writing space: Computers, hypertext, and the remediation of print. Mahwah, N.J.: Lawrence Erlbaum Associates.

Bourdieu, P. (1977). Outline of a Theory of Practice. Cambridge, MA: Cambridge University Press.

Bourdieu, P. (1990). The Logic of Praxis. Stanford: Stanford University Press.

Brachman, R. J., Khabaza, T., Kloesgen, W., Piatetsky-Shapiro, G., and Simoudis, E. (1996). Mining Business Databases. Communications of the ACM, 39(11), 42-48.

Breen, M. (1997). Information Does not Equal Knowledge: Theorizing the Political Economy of Virtuality. Journal of Computer Mediated Communication, 3(3).

Brown, S. (1995a). Postmodern Marketing. London: Routledge.

Brown, S. (1995b). Postmodern Marketing: No representation Without Taxation. Journal of the Market Research Society, 37(3), 287-310.

Caillois, R. (1979). Man, play, and games. New York: Schocken Books.

Campbell, C. (1987). The Romantic Ethic and the Spirit of Modern Consumerism. New York: Basil Blackwell Ltd.

Castells, M. (1996). The Rise of the Network Society. Malden, MA: Blackwell.

Castells, M. (1998, June 22-24). Information Technology, Globalization and Social Development. Paper presented at the Paper prepared for the UNRISD Conference on Information Technologies and Social Development, Palais des Nations, Geneva.

Cate, F. H. (1997). Privacy in the information age. Washington, D.C.: Brookings Institution Press.

Cavoukian, A., and Tapscott, D. (1997). Who Knows: Safeguarding Your Privacy in a Networked World. New York: McGraw-Hill.

Chen, Y., and Iyer, G. (2002). Consumer addressability and customized pricing. Marketing Science, 21(2), 197-208.

Cohen, L. (2003). A Consumer's Republic: The Politics of Mass Consumption in Postwar America. New York: A. A. Knopf.

Csikszentmihalyi, M. (1997). Finding flow: The psychology of engagement with everyday life. New York: BasicBooks.

Danet, B., Ruedenberg-Wright, L., and Rosenbaum-Tamari, Y. (1997). Hmmm...Where's that smoke coming from. Writing, play and performance on Internet Relay Chat. Journal of Computer-Mediated Communication [On-line], 2(4), Available: http://jcmc.huji.ac.il/vol2/issue4/danet.html.

DeCew, J. W. (1997). In Pursuit of Privacy : Law, Ethics, and the Rise of Technology. Ithaca: Cornell University Press.

Deighton, J. (1992). The Consumption of Performance. Journal of Consumer Research, 19(December), 362-372.

Delany, P., and Landow, G. P. (1991). Hypermedia and literary studies. Cambridge, Mass.: MIT Press. 
Dholakia, N., and Zwick, D. (2001). Privacy and Consumer Agency in the Information Age: Between Prying Profilers and Preening Webcams. Journal of Research for Consumers, 1(1), www.jrconsumers.com (Article 3).

Dreyfus, H. L. (1992). What computers still can't do: A critique of artificial reason. Cambridge, Mass.: MIT Press.

Dreyfus, H. L. (2001). On the Internet. London ; New York: Routledge.

Dholakia, N., and Zwick, D. (2001). Privacy and Consumer Agency in the Information Age: Between Prying Profilers and Preening Webcams. Journal of Research for Consumers, 1(1), www.jrconsumers.com (Article 3).

Dussart, C. (2001). Transformative Power of E-Business over Consumer Brands. European Management Journal, 19(6), 629-637.

Farrell, D. (2003). The real new economy. Harvard Business Review(October), 105-112. Fayyad, U. (2001). The Digital Physics of Data Mining. Communications of the ACM, 44(3), 62-65.

Fayyad, U., Piatetsky-Shapiro, G., and Smyth, P. (1996). The KDD Process for Extracting Useful Knowledge from Volumes of Data. Communications of the ACM, 39(11), 27-34.

Fayyad, U., and Uthurusamy, R. (1996). Data Mining and Knowledge Discovery in Databases. Communications of the ACM, 39(11), 24-26.

Fayyad, U., and Uthurusamy, R. (2002). Evolving data mining into solutions for insights. Communications of the ACM, 45(8), 28-31.

Feenberg, A. (1991). Critical Theory of Technology. New York: Oxford University Press. Feenberg, A. (1999). Questioning Technology. London and New York: Routledge.

Fine, G. A. (1996). Justifying work: Occupational rhetorics as resources in restaurant kitchens. Administrative Science Quarterly, 41(1), 90-115.

Firat, A., and Dholakia, N. (1998). Consuming People: From Political Economy to Theatres of Consumption. London: Routledge.

Firat, F. A., and Venkatesh, A. (1995). Liberatory Postmodernism and the Reenchantement of Consumption. Journal of Consumer Research, 22(Dec.), 239267.

Foucault, M. (1972). The Archaeology of Knowledge: A Discourse on Language (A. M. S. Smith, Trans.). New York: Pantheon Books.

Foucault, M. (1975). The Birth of the Clinic. New York: Vintage Books.

Foucault, M. (1977). Discipline and Punish: The birth of the prison (A. Sheridan, Trans.). New York: Vintage Books.

Foucault, M. (1978). The History of Sexuality (A. Hurley, Trans.). New York: Pantheon Books.

Fuchs, S. (2001). Against essentialism: A theory of culture and society. Cambridge, Mass.: Harvard University Press.

Geertz, C. (1973). Thick Description: Toward an Interpretive Theory of Culture. In The Interpretation of Cultures (pp. 3-30). New York, NY: Basic Books, Inc., Publishers.

Gibson, W. (1984). Neuromancer. New York: Ace Science Fiction Books.

Gordon, J. S. (1999). The Great Game: The Emergence of Wall Street as a World Power, 1653-2000. New York, NY: Scribner. 
Goss, J. (1995). We Know Who You Are and We Know Where You Live: The Instrumental Rationality of Geodemographic Systems. Economic Geography, 71(2), 171-198.

Grayson, K. (1995). The Dangers and Opportunities of Playful Consumption. In M. B. Holbrook (Ed.), Consumer Value (pp. 105-125). London and New York: Routledge.

Greenberg, P. (2002). CRM at the speed of light: Capturing and keeping customers in Internet real time (2nd ed.). Berkeley and London: McGraw-Hill.

Grönroos, C. (1995). Relationship marketing: The strategy continuum. Journal of the Academy of Marketing Science, 23(4), 252-254.

Habermas, J. (1984). The theory of communicative action. Boston: Beacon Press.

Hacking, I. (1982). Biopower and the Avalanche of Printed Numbers. Humanities in Society, 5(3/4), 279-295.

Hacking, I. (1983). Representing and Intervening. Cambridge: Cambridge University Press.

Hacking, I. (1986). Making up People. In T. C. Heller, M. Sosna and D. E. Wellbery (Eds.), Reconstructing Individuals (pp. 222-236). Stanford, CA: Stanford University Press.

Hayles, N. K. (1999). How we became posthuman: Virtual bodies in cybernetics, literature, and informatics. Chicago, Ill.: University of Chicago Press.

Heidegger, M. (1977). The Question Concerning Technology. New York: Harper Colophon Books.

Heim, M. (1987). Electric language: A philosophical study of word processing. New Haven: Yale University Press.

Heim, M. (1993). The Metaphysics of Virtual Reality. New York and Oxford: Oxford University Press.

Hoffman, D. L., and Novak, T. P. (1996). Marketing in Hypermedia Computer-Mediated Environments: Conceptual Foundations. Journal of Marketing, 80(July), 50-68.

Holbrook, M. B., Chestnut, R. B., Oliva, T., and Greenleaf, E. A. (1984). Play as Consumption Experience: The Role of Emotions, Performance, and Personality in the Enjoyment of Games. Journal of Consumer Research, 11(2), 728-739.

Holt, D. B. (1995). How Consumer Consume: A Typology of Consumption Practices. Journal of Consumer Research, 22(June), 1-16.

Huizinga, J. (1956). Homo Ludens - Vom Ursprung der Kultur im Spiel. Hamburg: Rowohlt.

Introna, L. D. (1997). Management, information and power: A narrative of the involved manager. London: Macmillan.

Jackson, J. (2002). Data mining: A conceptual overview. Communication of AIS, 8, 267296.

Keynes, J. M. (1964). The General Theory of Employment, Interest, and Money. New York: Harbinger.

Kling, R., and Allen, J. P. (1996). How the Marriage of Management and Computing Intensifies the Struggle for Personal Privacy. In D. Lyon and E. Zureik (Eds.), Computers, Surveillance, and Privacy (pp. 104-131). Minneapolis: University of Minnesota Press. 
Kozinets, R. V. (2002). The Field Behind the Screen: Using Netnography for Marketing Research in Online Communities. Journal of Marketing Research, 39(February), 61-72.

Landow, G. (1992). Hypertext: The Convergence of Contemporary Critical Theory and Technology. Baltimore, MD: The Johns Hopkins University Press.

Lanham, R. A. (1993). The electronic word: Democracy, technology, and the arts. Chicago: University of Chicago Press.

Latour, B. (1993). We have never been modern. Cambridge, Mass.: Harvard University Press.

Latour, B. (1996). Aramis, or, The love of technology. Cambridge, Mass.: Harvard University Press.

Laurel, B. (1991). Computers as theatre. Reading, Mass.: Addison-Wesley Pub.

Levine, R. (2000). The Cluetrain Manifesto: The End of Business as Usual. Cambridge, Mass.: Perseus Books.

Loveman, G. (2003). Dimonds in the Data Mine. Harvard Business Review(May), 109113.

MacKenzie, D. A., and Wajcman, J. (1999). The social shaping of technology (2nd ed.). Buckingham and Philadelphia: Open University Press.

Marx, G. T. (1988). Undercover: Police surveillance in America. Berkeley: University of California Press.

McConnell, B., and Huba, J. (2003). Creating customer evangelists: How loyal customers become a volunteer sales force. Chicago: Dearborn Trade Pub.

McKim, B. (2002). CRM: Beyond the hoopla. Target Marketing, 25(7), $38 \mathrm{ff}$.

Merleau-Ponty, M. (1962). The Phenomenology of Perception. London: Routledge.

Metha, M. D., and Darier, E. (1998). Virtual Control and Disciplining on the Internet: Electronic Governmentality in the New Wired World. The Information Society, 14, 107-116.

Miller, P., and Rose, N. (1997). Mobilizing the Consumer. Theory, Culture, and Society, 14(1), 1-36.

Mingers, J. (2001). Embodying information systems: The contribution of phenomenology. Information and Organization, 11, 103-128.

Mulvenna, M. D., Anand, S. S., and Buchner, A. G. (2000). Personalization on the Net using Web mining. Association for Computing Machinery. Communications of the ACM, 43(8), 122-125.

Mumford, L. (1967). The myth of the machine. New York: Harcourt Brace and World.

Nakamura, L. (2002). Cybertypes: Race, ethnicity, and identity on the Internet. New York and London: Routledge.

O'Dell, S. M., and Pajunen, J. A. (1997). The butterfly customer: Capturing the loyalty of today's elusive consumer. Toronto and New York: J. Wiley \& Sons Canada.

Ong, W. J. (1982). Orality and Literacy: The Technologizing of the Word. London and New York: Methuen.

Payne, A. (1995). Advances in relationship marketing. London: Kogan Page.

Peppers, D., and Rogers, M. (1993). The one to one future: Building relationships one customer at a time. New York: Currency Doubleday.

Peppers, D., and Rogers, M. (1997). Enterprise One-To-One: Tools for Competing in the Interactive Age (1st ed.). New York: Currency Doubleday. 
Poster, M. (1990a). Foucault and databases. Discourse, 12(2), 110-127.

Poster, M. (1990b). The Mode of Information. Chicago: The University of Chicago Press. Poster, M. (1995). The Second Media Age. Cambridge: Polity Press.

Rigby, D. K., Reichheld, F. F., and Schefter, P. (2002). Avoid the four perils of CRM. Harvard Business Review, 80(2), 101-109.

Roberts, M. (1999). Transforming the role of marketing in the chemical industry: New information, new opportunities. Chemical Week, 161(45), S18-S20.

Robey, D., Schwaig, K. S., and Jin, L. (2003). Intertwining material and virtual work. Information and Organization, 13, 111-129.

Rose, N. (1988). Calculable minds and manageable individuals. History of the Human Sciences, 1(2), 179-200.

Rud, O. (2001). Data mining cookbook: Modeling data for marketing, risk and customer relationship management. New York: Wiley.

Satur, R., and Zhi-Qiang, L. (1996). A context-driven intelligent database processing system using object-oriented fuzzy cognitive maps. International Journal of Intelligent Systems, 11, 671-689.

Sawchuck, K. (1994). Semiotics, cybernetics, and the ecstasy of marketing communication. In D. Kellner (Ed.), Baudrillard: A critical reader (pp. 89-116). Cambridge, MA: Blackwell.

Schiller, H. I. (1992). Mass communications and American empire (2nd ed.). Boulder: Westview Press.

Schiller, H. I. (1996). Information inequality: The deepening social crisis in America. New York: Routledge.

Schlosser, E. (2001). Fast food nation: The dark side of the all-American meal. Boston: Houghton Mifflin.

Schroter, H. G. (1997). Marketing als angewandte Sozialtechnik und Veranderungen im Konsumverhalten. In H. Siegrist, H. Kaelble and J. Kocka (Eds.), Europaische Konsumgeschichte (pp. 615-647). Frankfurt: Campus.

Shilling, C. (1993). The Body and Social Theory. London: Sage.

Smith, M. R., and Marx, L. (1994). Does technology drive history?: The dilemma of technological determinism. Cambridge, Mass.: MIT Press.

Sotto, R. (1997). The Virtual Organization. Accounting, Management and Information Technology, 7(1), 37-51.

Sterne, J. (2001). World Wide Web marketing integrating the web into your marketing strategy, from http://www.netLibrary.com/urlapi.asp?action=summary\&v=1\&bookid=63088

Stone, A. R. (2000). Will the real body please stand up? Boundary stories about virtual cultures. In D. Bell and B. M. Kennedy (Eds.), The Cybercultures Reader (pp. 504-528). London and New York: Routledge.

Swift, R. S. (2001). Accelerating Customer Relationships: Using CRM and relationship technologies. Upper Saddle River, NJ: Prentice Hall.

Turkle, S. (1995). Life on the Screen. New York, NY: Touchstone.

Vavra, T. G. (1992). Aftermarketing: How to keep customers for life through relationship marketing. Homewood, Ill.: Business One Irwin.

Virilio, P. (1989). War and cinema: The logistics of perception. London and New York: Verso. 
Virilio, P. (1994). The Vision Machine. Bloomington: Indiana University Press.

Virilio, P. (2000). The Information Bomb. London: Verso.

Vriens, M., and Grigsby, M. (2001). Building profitable online customer-brand relationships. Marketing Management, 10(4), 34-39.

Winner, L. (1977). Autonomous technology: Technics-out-of-control as a theme in political thought. Cambridge, Mass.: MIT Press.

Winner, L. (1999). Do artifacts have politics? In D. A. MacKenzie and J. Wajcman (Eds.), The social shaping of technology (2nd ed., pp. 28-40). Buckingham and Philadelphia: Open University Press.

Zwick, D., and Dholakia, N. (forthcoming). Whose Identity is it Anyway? Consumer Representation in the Age of Database Marketing. Journal of Macromarketing.

1 To illustrate this point, consider the fast food industry. The introduction of division of labor and assembly-line work processes, automated machinery, and image-based registers not only increased a restaurant's operational efficiency, it also progressively deskilled (and reskilled?) the fast food worker so as to make him or her more machine-like in the eyes of the engineer designing production equipment and the manager buying it (Fine, 1996; Schlosser, 2001). In addition, the rise of fast food technology also changed the meaning of home-cooking and the role of the home maker, traditionally the housewife (Feenberg, 1991).

2 With information technology (IT) becoming a critical CRM enabler (Goodhue, Wixom, and Watson, 2002), we believe CRM and electronic CRM (eCRM) will converge, if they have not already done so. To simplify things, we use the original acronym CRM to denote both types.

3 The New Yorker, September 6, 1993. In Cohen, L. (2003), p. 300.

4 In fact, following Manuel Castells (1996) we could speak of an "extended" form of agency because the networked individual is connected to flows of information that are by the nature of the medium global. Thus, Castells conceives of the individual in the network society as an agent who can act in an extended time-space continuum.

5 At the leading edge of database marketing, however, some limited form of consumer control is being offered. Amazon.com uses "cookies" to recognise returning customers, and then offers them dozens of product recommendations. After each recommendation, a hyperlink "Why was I recommended this?" is offered. Clicking on this hyperlink offers a glimpse into the section of the Amazon database that stores previous correlated purchases of the customer. The customer then has options of clicking on "Not Interested" in that specific recommendation, or to intensify or dilute the recommendation algorithm by indicating the intensity of preference for the previously purchased correlated items on a 5-point scale.

6 Even in the case of the Amazon.com, wherein a limited form of control of the database is offered to the customer, the database creates bizarre product recommendations when a family computer is used to order items. The database representations of diverse family members - the dog lover, the postmodern critical thinker, the hip-hop music fan, and the romance novel reader - get associated with the same "cookie", leading to a hodgepodge of inconsistent recommendations.

7 After the events of September 11, 2001 the importance of databases in controlling global terrorist threats will likely increase.

8 We use the term cognitively present to denote that even if the body may be considered absent or irrelevant for the construction of virtual identity, cognitive labor of some agent is still needed in the process. 
9 This term is borrowed from John Deighton (1997), Guest Lecture, School of Business Administration, University of Rhode Island, Kingston, RI, USA.

10 In Holt's anthropological work such consumption objects are mostly material objects like, for example, t-shirts and hats that symbolize one's affinity to a specific sports team. Based on these objects people come together, identify, and interact with each other and other groups. Hence, in this widened sense of consumption anything consumers use as resources to engage in interaction is a consumption object. In virtual worlds, consumption objects may be both material (for example discussion groups that formed around Starbucks Café [Kozinets, 1999]) or virtual (for example Amazon.com).

11 A similar argument that connects play and social status and recognition has been advanced by Clifford Geertz in his essay on the Balinese cockfights, albeit from a different perspective. Looking at the betting system around the cockfights, he describes what he calls “deep play.” Deep play results when the matched competitors, in Geertz's case the cocks, are as equal in strength and acumen as possible. Obviously, the strategy of equally matching opponents is a deliberate attempt to increase volatility of the game. However, even more important than that is the fact that the stake of the center bet is very high. Indeed, the center bet "makes the game" (Geertz, 1973, p. 216) in the sense of defining it as "deep" or "shallow." To explain the seductiveness of deep play, its experiential richness, and its complexity as an object of consumption, it is necessary to understand that the objective of playing is not solely driven by instrumental purpose such as material gain. Indeed, what is at stake when large sums of money are waged against each other is much greater than return on investment: "namely, esteem, honor, dignity, respect--in a word [...] status" (Geertz, 1973, p. 218). To call such serious money betting competition for social status a game seems contradictory. Johan Huizinga (1950) reminds us however that such playing can take place with the utmost seriousness. The opposition between play and earnestness is always a tenuous one.

12 See Danet et al. (1997) for an elaboration on these types of play. 